\title{
Desempenho termoenergético e luminoso de uma edificação de escritório com a utilização de vidros eletrocrômicos
}

\section{Thermoenergetic and luminous performance of a office building with the use of electrochromic glasses}

\author{
Joseane da Silva Porto ${ }^{1}$, Julye Moura Ramalho de Freitas ${ }^{2}$, \\ Raphael Dorneles Caldeira Balboni ${ }^{1}$, Suzana Treichel ${ }^{3}$, \\ Eduardo Grala da Cunha ${ }^{4}$, Renie Santos de Mattos ${ }^{5}$, Rodrigo Karini Leitzke ${ }^{1}$, \\ Camila Monteiro Cholant ${ }^{1}$, César Antonio Oropesa Avellaneda ${ }^{1}$
}

\begin{abstract}
${ }^{1}$ Universidade Federal de Pelotas, UFPel, Cdtec, Pelotas, Rio Grande do Sul, RS, Brasil.
${ }^{2}$ Arquiteta e Urbanista, Mestre pelo Programa de Pós-Graduação em Arquitetura e Urbanismo (PROGRAU-UFPEL) Pelotas, Rio Grande do Sul, RS, Brasil.

${ }^{3}$ Tecnóloga em Construção de Edifícios, Mestre pelo Programa de Pós-Graduação em Arquitetura e Urbanismo (PROGRAU-UFPEL) Pelotas, Rio Grande do Sul, RS, Brasil.

${ }^{4}$ Universidade Federal de Pelotas, UFPel, Faculdade de Arquitetura, Pelotas, Rio Grande do Sul, RS, Brasil.

${ }^{5}$ Universidade Federal de Pelotas, UFPel, Instituto de Ciências Humanas, Pelotas, Rio Grande do Sul, RS, Brasil. e-mail: joseaneclmd@gmail.com, raphael.balboni@gmail.com,juramalhof@hotmail.com, suzanatreichel@gmail.com, eduardogralacunha@yahoo.com.br, alemaorenie@gmail.com,rodrigokarinileitzke@gmail.com, camila.scholant@gmail. com, cesaravellaneda@gmail.com
\end{abstract}

\section{RESUMO}

Este trabalho tem como objetivo analisar o desempenho termoenergético e luminoso de uma edificação com atividades características de escritórios com vidros eletrocrômicos através de estudo comparativo, considerando vidros comuns de $3 \mathrm{~mm}$ e $6 \mathrm{~mm}$. Para a simulação computacional foi utilizado o programa EnergyPlus. Foram realizadas simulações com o vidro comum Clear $3 \mathrm{~mm}$ e de $6 \mathrm{~mm}$ e o vidro eletrocrômico Sage Glass $9 \mathrm{~mm}$ com a finalidade de analisar a iluminação, o consumo de energia, e o nível de conforto térmico provenientes da climatização artificial e da ventilação natural, respectivamente. As simulações foram realizadas em duas zonas bioclimáticas, na zona bioclimática 2 (ZB 2) e na zona bioclimática 8 (ZB 8), onde utilizou-se os arquivos climáticos da cidade de Camaquã e da cidade de Manaus, respectivamente. Com os resultados obtidos foi possível observar que a edificação com vidros eletrocrômicos apresentou melhor nível de conforto térmico nas horas ocupadas, e que o consumo de energia para resfriamento diminui conforme o aumento da coloração principalmente na ZB 8, por se tratar de uma região com clima quente. Notou-se que na ZB 2 em alguns meses do ano o vidro eletrocrômico permanecia totalmente descolorido, já que a temperatura de setpoint era sempre maior que a temperatura externa. Também foi possível observar que é fundamental analisar a orientação solar para o melhor posicionamento das aberturas na edificação.

Palavras-chave: vidros eletrocrômicos, iluminação, conforto térmico, eficiência energética.

\section{ABSTRACT}

This work aims to analyze the thermoenergetic and luminous performance of a building with office characteristic activities with electrochromic glasses through comparative study, considering common glasses of $3 \mathrm{~mm}$ and $6 \mathrm{~mm}$. For the computational simulation were used the EnergyPlus software. Simulations were performed with the Clear common glass Clear of $3 \mathrm{~mm}$ and $6 \mathrm{~mm}$ and the electrochromic glass Sage Glass $9 \mathrm{~mm}$ with the purpose of analyzing the lighting, the energy consumption, and the level of thermal comfort coming from the artificial climatization and the natural ventilation, respectively. The simulations were performed in two bioclimatic zones, in bioclimatic zone 2 (ZB 2) and in bioclimatic zone 8 (ZB 8), where it was used the climate files from the city of Camaquã and the city of Manaus, respectively. With the results obtained 
it was possible to observe that the building with electrochromic glasses presented the best level of thermal comfort in the hours occupied, and that the energy consumption for cooling decreases as the coloration increases, especially in the ZB 8 , since it is a region of warm weather. It was noted that in the ZB 2 in some months of the year, the electrochromic glass remains totally discolored, since the temperature of setpoint was always higher than the external temperature. It was also possible to observe that it is fundamental analyze the solar orientation for the best positioning of the building's openings.

Keywords: electrochromic glasses, illumination, thermal comfort, energy efficiency

\section{INTRODUÇÃO}

O uso excessivo do vidro na arquitetura, sem uma preocupação simultânea com elementos de proteção, tipo adequado de vidro e orientação solar, foi muito frequentemente observado nos edifícios, principalmente após a segunda guerra mundial. Como se tinha energia em abundância e a um custo irrisório, a integração entre a edificação e o clima foi deixada para segundo plano, ocasionando edificações dependentes de fontes artificiais para condições mínimas de conforto de acordo com [1].

O vidro é um elemento indispensável na construção civil, porém como já mencionado a utilização desse elemento deve estar diretamente ligada à preocupação com o controle de consumo energético, já que este permite a entrada dos raios luminosos e consequentemente da radiação solar. $\mathrm{O}$ uso excessivo do vidro em edificações apesar de proporcionar um bom nível de iluminação, transparência e integração com o ambiente externo, pode causar desconforto térmico no interior dos ambientes, devido aos ganhos de radiação solar, e/ou devido às elevadas trocas de calor por condução com o meio exterior.

Para conseguir a integração do vidro na edificação, levando em consideração o fator conforto térmico e luminoso, estão sendo desenvolvidos estudos com os vidros eletrocrômicos, que são vidros que apresentam transmitância variável e prometem ajudar tanto no conforto luminoso quanto no conforto térmico. Vários estudos relacionados aos vidros eletrocrômicos estão sendo desenvolvidos, entre eles estão os trabalhos de [2], [3] e [4].

A tecnologia dos vidros eletrocrômicos é conhecida dede o século XIX, esse tipo de vidro consegue imitar a função da íris nos olhos dos mamíferos, variando a transmissão global enquanto mantém uma visão clara [5]. Devido à variedade do potencial de aplicações que os dispositivos eletrocrômicos proporcionam, houve um aumento considerável nas pesquisas e no desenvolvimento dos mesmos. Os dispositivos eletrocrômicos podem ser utilizados em retrovisores de veículos automotores, tetos solares e janelas inteligentes [6] e [7].

Dispositivos eletrocrômicos ou janelas inteligentes apresentam transmitância variável, proporcionam bom contraste visual entre os ambientes interiores e exteriores e, ainda, são capazes de minimizar a passagem dos raios ultravioleta e infravermelho aos ambientes internos. Desta maneira, em locais com clima quente, contribuem para a redução do aquecimento desses ambientes, adequando sua luminosidade e calor, e, consequentemente diminuindo o consumo de energia [8] e [9].

Uma janela eletrocrômica muda de cor devido à aplicação de potencial ou corrente, ou seja, é essencialmente uma célula eletroquímica onde o eletrodo de trabalho (eletrocrômico) está separado do contra eletrodo através de um eletrólito (sólido, líquido ou gel) e a mudança de cor ocorre devido ao carregamento e descarregamento da célula eletroquímica por meio de um potencial aplicado ou corrente elétrica.

Em seus estudos [1], explica que durante a aplicação deste potencial ocorre a dupla inserção de íons e elétrons que mudam o estado de oxidação do eletrodo de trabalho e, consequentemente, muda sua coloração. A aplicação do potencial contrário provoca à extração dos íons e elétrons inseridos no eletrodo de trabalho e consequentemente a descoloração da janela.

Os dispositivos eletrocrômicos conhecidos permitem regular a reflexão ou transmissão da luz quando uma pequena voltagem é aplicada em seus condutores eletrônicos. Deste modo, as janelas inteligentes possibilitam o controle da luminosidade e do calor em ambientes fechados, reduzindo o consumo de energia. De acordo com [10], o uso de janelas inteligentes é fundamental na redução de energia nos edifícios, além de preservar a visibilidade aumentando o conforto e a produtividade dos que trabalham no interior da edificação.

Este trabalho tem como objetivo avaliar a eficácia dos vidros eletrocrômicos sobre o comportamento térmico, luminoso e eficiência energética de uma edificação com atividades características de escritório nas zonas bioclimáticas brasileiras 2 e 8, através de simulação computacional utilizando o software EnergyPlus ${ }^{\circledR}$ versão 8.4.

\section{MATERIAIS E MÉTODOS}

O presente artigo é um estudo exploratório, visando investigar o desempenho dos vidros eletrocrômicos para o conforto luminoso, conforto térmico e eficiência energética em uma edificação comercial. Foi desenvolvido através de simulação computacional, com o uso do software, EnergyPlus ${ }^{\circledR}$ versão 8.4. 
Este trabalho foi dividido em 5 etapas, na primeira foi feita uma revisão bibliográfica, abrangendo principalmente o tema: vidros eletrocrômicos, sua tecnologia e propriedades. Na segunda etapa foram definidos e modelados no software SketchUp com o plugin Legacy Open Studio os modelos a serem estudados. Na terceira etapa foram feitas as configurações dos modelos com o IDF Editor do software EnergyPlus. Na quarta etapa foram feitas as simulações computacionais dos modelos, de modo a determinar consumo energético, conforto térmico e lumínico em cada situação simulada. Na quinta etapa os resultados foram analisados e por fim foi realizada uma comparação entre o desempenho térmico, eficiência energética e o desempenho luminoso da edificação em cada caso.

\subsection{Definição e modelagem do objeto de estudo}

Para o estudo, foi desenvolvido um modelo fictício com atividades características de escritório, com duas salas (escritórios) e com uma circulação, para as salas foi atribuída uma dimensão de $4 \mathrm{~m}$ x 4m, com um pé-direito de 3m, já para a circulação, $2 \mathrm{~m} \times 4 \mathrm{~m}$, também com pé-direito de $3 \mathrm{~m}$. A figura 1, ilustra a modelagem da edificação em estudo no software Sketchup 2015, com o plugin Legacy Open Studio 1.0.13. Foram simulados 4 modelos com diferentes posicionamentos de aberturas (tabela 1), tendo como finalidade avaliar o desempenho termoenergético da edificação em diferentes orientações solares.

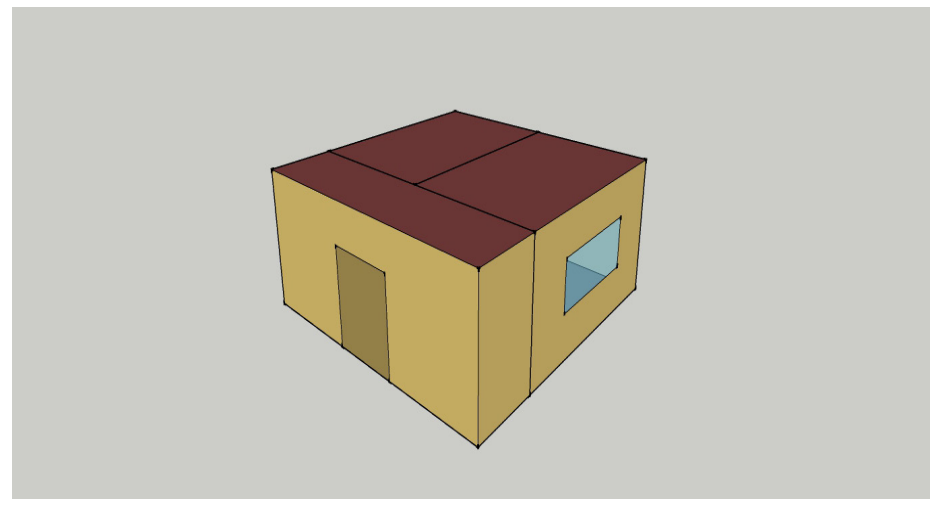

Figura 1: Apresentação do modelo do estudo

Tabela 1: Modelos simulados.

\begin{tabular}{l|l}
\hline MODELOS & JANELAS \\
\hline & $\begin{array}{l}\text { Sala 1 - janelas norte e oeste } \\
\text { Sala 2 - janelas norte e leste }\end{array}$ \\
\hline Modelo 2 & $\begin{array}{l}\text { Sala 1 - janelas sul e oeste } \\
\text { Sala 2 - janelas sul e leste }\end{array}$ \\
\hline Moldelo 1 & $\begin{array}{l}\text { Sala 1 - janelas norte e sul } \\
\text { Sala 2 - janelas norte e sul }\end{array}$ \\
\hline
\end{tabular}




\subsection{Configurações dos modelos}

\subsubsection{Configurações para as simulações termoenergéticas}

As configurações de uso, ocupação, iluminação e equipamentos foram feitas de modo a atender os pré-requisitos específicos do Regulamento Técnico da Qualidade para o Nível de Eficiência Energética de Edificações Comerciais (RQT-C) para um edifício de escritórios, permitindo a avaliação do consumo anual de energia e o conforto térmico do edifício em estudo. O RTQ-C é a normativa de eficiência energética para edifícios comerciais, públicos e de serviços [11].

A envoltória foi configurada de modo que atendesse o nível de eficiência energética "A" do RTQ-C para a zona bioclimática 2. A mesma configuração foi adotada para as simulações realizadas na zona bioclimática 8. No modelo projetou-se a implantação de um vidro eletrocrômico, de um vidro comum com $3 \mathrm{~mm}$ de espessura e de um vidro comum com espessura de $6 \mathrm{~mm}$, tendo como objetivo comparar o desempenho termoenergético da edificação através da simulação computacional. A Tabela 2 abaixo descreve os materiais adotados e as transmitâncias térmicas obtidas.

Tabela 2: Materiais e transmitâncias térmicas.

\begin{tabular}{|c|c|c|c|}
\hline & MATERIAL & ESPESSURA TOTAL & TRANSMITÂNCIA \\
\hline \multirow{4}{*}{$\begin{array}{c}\text { Paredes Externas e } \\
\text { Internas }\end{array}$} & Argamassa de reboco externo $1,00 \mathrm{~cm}$ & \multirow{4}{*}{$14,46 \mathrm{~cm}$} & \multirow{4}{*}{$1,00 \mathrm{~W} / \mathrm{m}^{2} \cdot \mathrm{K}$} \\
\hline & Poliestireno extrudado $2,46 \mathrm{~cm}$ & & \\
\hline & Tijolo cerâmico maciço $10,00 \mathrm{~cm}$ & & \\
\hline & Argamassa de reboco interno $1,00 \mathrm{~cm}$ & & \\
\hline \multirow{4}{*}{ Cobertura } & Poliestireno extrudado $2,46 \mathrm{~cm}$ & \multirow{4}{*}{$14,46 \mathrm{~cm}$} & \multirow{4}{*}{$0,50 \mathrm{~W} / \mathrm{m}^{2} . \mathrm{K}$} \\
\hline & Tijolo cerâmico maciço $10,00 \mathrm{~cm}$ & & \\
\hline & Argamassa de reboco interno $1,00 \mathrm{~cm}$ & & \\
\hline & Argamassa de reboco externo $1,00 \mathrm{~cm}$ & & \\
\hline \multirow{4}{*}{ Piso } & Aterro $2,50 \mathrm{~cm}$ & \multirow{4}{*}{$16,00 \mathrm{~cm}$} & \multirow{4}{*}{$3,40 \mathrm{~W} / \mathrm{m}^{2} . \mathrm{K}$} \\
\hline & Contrapiso de concreto $10,00 \mathrm{~cm}$ & & \\
\hline & Argamassa $2,5 \mathrm{~cm}$ & & \\
\hline & Piso cerâmico $1,00 \mathrm{~cm}$ & & \\
\hline
\end{tabular}

A Tabela 3 apresenta as transmitâncias visíveis dos vidros utilizados nas simulações.

Tabela 3: Transmitâncias Visíveis.

\begin{tabular}{c|c}
\hline VIDROS & TRANSMITÂNCIAS \\
\hline Vidro comum (Comum $3 \mathrm{~mm})$ & 0,898 \\
\hline Vidro comum (Comum 6mm) & 0,884 \\
\hline Vidro eletrocrômico (Sage Glass 9mm) & 0,512 \\
\hline
\end{tabular}

Para que fosse possível simular o comportamento térmico de um vidro eletrocrômico foi necessário utilizar o recurso EMS (Energy Management System) do software EnergyPlus, ferramenta capaz de acessar uma ampla variedade de dados "sensores" e usar esses dados para direcionar vários tipos de ações de controle [12]. O modelo foi implementado utilizando o vidro eletrocrômico nas fases descolorida e totalmente colorido. Os sensores aplicados nestas simulações foram o da temperatura externa e o setpoint escolhido foi de $23^{\circ} \mathrm{C}$ para ZB2 e de $26^{\circ} \mathrm{C}$ para ZB8, portanto, o vidro está totalmente colorido quando a temperatura externa estiver maior ou igual a $23^{\circ} \mathrm{C}$ e $26^{\circ} \mathrm{C}$ para ZB2 e ZB8, respectivamente [13]. Sendo assim, na zona bioclimática 2 , nos meses de maio a outubro o vidro fica totalmente descolorido na maior parte do tempo, já que a temperatura externa é menor que o setpoint, e na zona bioclimática 8 ele permanece descolorido durante a noite, variando a coloração de $50 \%$ a $100 \%$ durante o dia, pois a temperatura é maior ou igual ao setpoint durante o dia.

A ventilação natural foi configurada através do Airflownetwork, o que possibilita as aberturas das janelas e portas definindo os limites de temperatura para que ocorra a ventilação natural. A ventilação natural foi permitida por $24 \mathrm{~h}$, sendo estabelecida uma temperatura mínima de resfriamento e uma máxima de aquecimento. Quando a temperatura interna estiver superior a $26^{\circ} \mathrm{C}$, e a externa inferior em até $5^{\circ} \mathrm{C}$, as janelas abrem.

Para o sistema de condicionamento de ar adotado foi split com coeficiente de performance (COP) de $3,24 \mathrm{~W}_{\text {térmico }}{ }^{\prime}$ $\mathrm{W}_{\text {elétrico }}$ (Watts de capacidade de refrigeração por Watt potência). O sistema de condicionamento de ar foi configurado para 
o ano todo, no qual a temperatura de setpoints para aquecimento foi de $22^{\circ} \mathrm{C}$ e de resfriamento de $26,5^{\circ} \mathrm{C}$, acordando com a NBR 16401 [14].

Os arquivos climáticos utilizados para as simulações foram: da cidade de Camaquã para representar a zona bioclimática 2, por ser uma das zonas mais frias e apresenta temperaturas extremas no inverno, tendo as quatro estações bem definidas, e da cidade de Manaus para representar a zona bioclimática 8, já que está apresenta as temperaturas mais elevadas o ano todo. Os arquivos estão disponibilizados no site do Laboratório de eficiência energética em edificações (LABEEE), elaborado por Maurício Roriz (ANTAC - GT Conforto e Energia) através dos dados registrados pelo Instituto Nacional de Meteorologia (INMET) no período de 2001 a 2010.

\subsubsection{Configurações para simulação de conforto luminoso}

Para a simulação do conforto luminoso, foi utilizado o mesmo o modelo computacional (maquete eletrônica) desenvolvido no software Sketchup 2015, com o plugin Legacy Open Studio 1.0.13 e simulado no software EnergyPlus 8.4. Para análise de luz natural colocou-se um ponto de análise no centro em cada sala a uma altura de $0,75 \mathrm{~m}$.

\subsection{Simulações computacionais}

Para a análise do desempenho térmico e luminoso da edificação com os três diferentes tipos de vidros, foram simulados 48 casos distintos, especificados na Tabela 4 a seguir:

Tabela 4: Modelos simulados.

\begin{tabular}{|c|c|c|c|c|}
\hline MODELOS & JANELAS & CONFIGURAÇÕES & VIDROS & $\begin{array}{c}\text { ZONAS } \\
\text { BIOCLIMÁTICAS }\end{array}$ \\
\hline \multirow{3}{*}{ Mфdelo } & \multirow{3}{*}{$\begin{array}{c}\text { Sala } 1 \text { - janelas } \\
\text { norte e oeste } \\
\text { Sala } 2 \text { - janelas } \\
\text { norte e leste }\end{array}$} & \multirow{3}{*}{$\begin{array}{l}\text { Ar condicionado e } \\
\text { Ventilação natural }\end{array}$} & Vidro Comum 3mm & \multirow{3}{*}{ ZB 2 e ZB 8} \\
\hline & & & Vidro Comum 6mm & \\
\hline & & & Vidro eletrocrômico & \\
\hline \multirow{3}{*}{ Mфdelo 2} & \multirow{3}{*}{$\begin{array}{l}\text { Sala } 1 \text { - janelas } \\
\text { sul e oeste } \\
\text { Sala } 2 \text { - janelas } \\
\text { sul e leste }\end{array}$} & \multirow{3}{*}{$\begin{array}{l}\text { Ar condicionado e } \\
\text { Ventilação natural }\end{array}$} & Vidro Comum $3 \mathrm{~mm}$ & \multirow{3}{*}{ ZB 2 e ZB 8} \\
\hline & & & Vidro Comum $6 \mathrm{~mm}$ & \\
\hline & & & Vidro eletrocrômico & \\
\hline \multirow{3}{*}{ delo $\beta$} & \multirow{3}{*}{$\begin{array}{c}\text { Sala } 1 \text { - janelas } \\
\text { norte e sul } \\
\text { Sala } 2 \text { - janelas } \\
\text { norte e sul }\end{array}$} & \multirow{3}{*}{$\begin{array}{l}\text { Ar condicionado e } \\
\text { Ventilação natural }\end{array}$} & Vidro Comum 3mm & \multirow{3}{*}{ ZB 2 e ZB 8} \\
\hline & & & Vidro Comum 6mm & \\
\hline & & & Vidro eletrocrômico & \\
\hline & Sala 1 - janelas & \multirow{3}{*}{$\begin{array}{l}\text { Ar condicionado e } \\
\text { Ventilação natural }\end{array}$} & \multirow{3}{*}{ Vidro Comum $3 \mathrm{~mm}$} & \multirow{3}{*}{ ZB 2 e ZB 8} \\
\hline Mфdelo 4 & $\begin{array}{c}\text { norte, sul e } \\
\text { oeste } \\
\text { Sala } 2 \text { - janelas } \\
\text { norte, sul e }\end{array}$ & & & \\
\hline & leste & & & \\
\hline
\end{tabular}

\subsection{Método de análise dos resultados}

\subsubsection{Análise do conforto térmico}

A avaliação do conforto térmico foi feita pelo modelo adaptativo de [15] para a [16]. Este modelo é válido somente para ambientes climatizados naturalmente e relaciona as temperaturas externas e internas dos ambientes. Através da temperatura externa o modelo determina a temperatura operativa de conforto através da Equação 1 abaixo.

$$
\text { Toc }=18,9+0,255 \mathrm{~T}_{\mathrm{ext}}
$$


Onde:

$\mathrm{T}_{\mathrm{oc}}=$ Temperatura operativa de conforto;

$\mathrm{T}_{\mathrm{ext}}=$ Temperatura média mensal externa.

Uma oscilação da temperatura operativa interna em relação à temperatura operativa de conforto entre $+2,5^{\circ} \mathrm{C}$ e $-2,2^{\circ} \mathrm{C}$ estabelece uma aceitabilidade de $90 \%$, e entre $+3,5^{\circ} \mathrm{C}$ e $-3,2^{\circ} \mathrm{C}$ uma aceitabilidade de $80 \%$ [16]. Para análise do conforto térmico da edificação simulada calculou-se o número de horas em conforto para $80 \%$ de pessoas satisfeitas. $\mathrm{O}$ modelo de [15] baseia-se em um critério de $10 \%$ de insatisfação para conforto térmico em geral mais $10 \%$ de desconforto para térmico local [16].

\subsubsection{Análise do consumo energético}

A partir das configurações gerais do modelo e a configuração de um sistema de ar condicionado e após rodar as simulações, o software EnergyPlus fornece um arquivo no formato $\mathrm{html}$ com os dados de consumo energético da edificação configurada. Os resultados são dados em $\mathrm{kWh} /$ ano e são divididos em consumo energético para aquecimento, resfriamento e ainda consumo energético para iluminação e equipamentos. A análise do consumo energético se deu através da comparação do consumo energético nos casos distintos com cada tipo de vidro.

\subsubsection{Análise do conforto luminoso}

A análise da iluminação natural nos ambientes foi feita através de dois métodos. Pelo método da iluminância natural útil, mais conhecido como UDI, onde foi verificada a porcentagem das horas do ano de $8 \mathrm{~h}$ até às $18 \mathrm{~h}$ em que a iluminância no ambiente fica entre 100lux e 2000lux. O segundo método foi o da Autonomia de Luz Natural, também conhecido como DA, neste foi verificado a porcentagem das horas do ano entre $8 \mathrm{~h}$ e $18 \mathrm{~h}$ em que a iluminância no ambiente fica acima de $5001 \mathrm{ux}$.

\section{RESULTADOS E DISCUSSÃO}

\subsection{Conforto térmico}

\subsubsection{Conforto térmico e consumo de energia para ZB2}

Nos casos simulados foram coletados os dados de temperatura operativa do ambiente e das temperaturas médias mensais externas que possibilitaram calcular, com o auxílio do programa Microsoft Excel®, o nível de conforto térmico.

Já a análise dos resultados do consumo de energia foi obtida através da comparação dos casos simulados, alterando apenas de ventilados naturalmente para condicionamento de ar. Em todos os casos simulados o valor encontrado para o consumo de energia em iluminação foi de $641,41 \mathrm{kWh} /$ ano e para equipamentos o valor obtido é de $322,24 \mathrm{kWh} /$ ano, levando em consideração um ciclo de operação diária de 10 horas. Apesar dos valores de consumo em iluminação e equipamento serem significativos dentro do consumo de energia da edificação por apresentarem valores constantes em todos os casos, esses dados não foram considerados nas comparações apresentadas a seguir.

A figura 2, mostra o percentual de horas de conforto térmico e o consumo total de energia, para os vidros Comum de $3 \mathrm{~mm}, 6 \mathrm{~mm}$ e o vidro eletrocrômico Sage Glass de 9mm na edificação do Modelo 1 dentro das 10 horas de ocupação diária. 


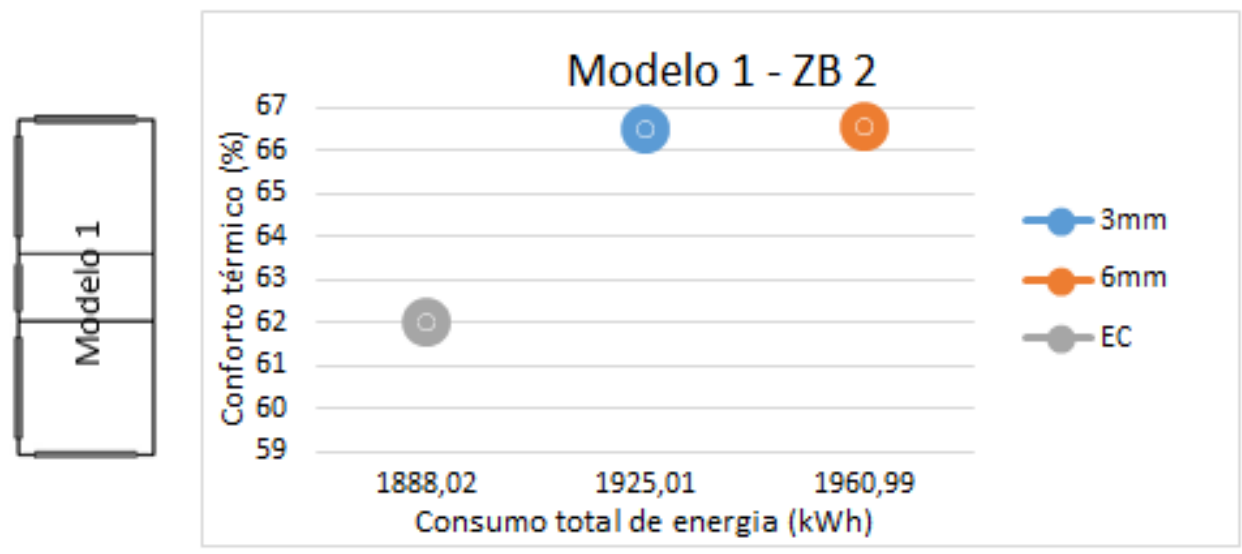

Figura 2: Consumo de energia e conforto térmico do Modelo 1 na ZB2.

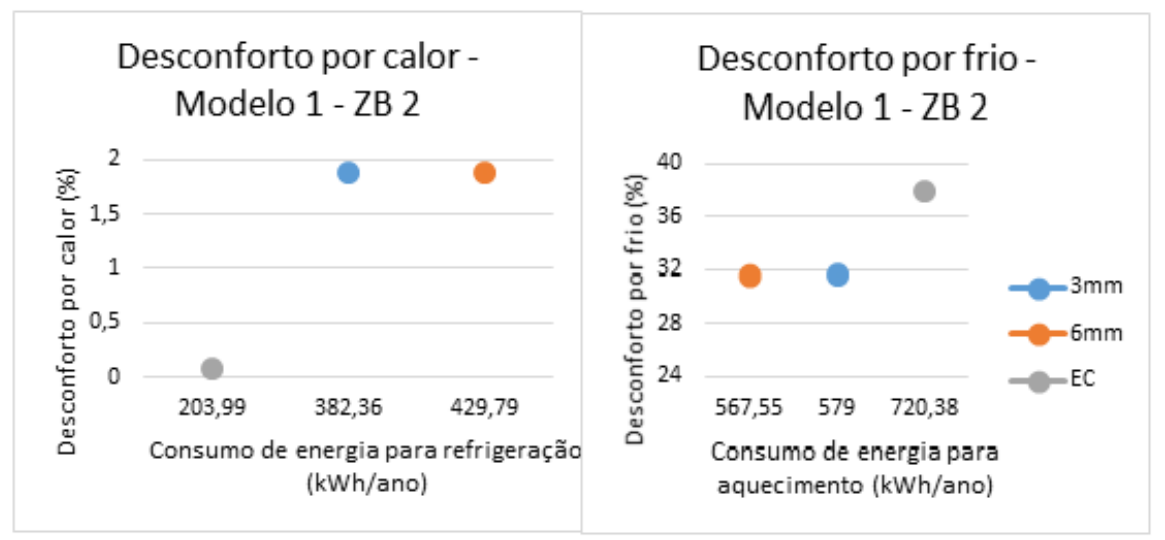

Figura 3: Consumo de energia para aquecimento e refrigeração versus desconforto por calor e frio do Modelo 1 na ZB2.

No Modelo 1, o vidro eletrocrômico foi o que apresentou melhores resultados mesmo tendo um percentual de horas em conforto térmico menor que os outros vidros em análise, e o vidro Comum de $6 \mathrm{~mm}$ é o pior caso simulado para este modelo de edificação (Figura 2).

Os resultados mostraram que este Modelo é o que apresenta menor desconforto por frio entre todos os casos simulados, isso ocorre porque as aberturas estão posicionadas para o norte e oeste e para norte e leste nas salas 1 e 2 , respectivamente.

O desconforto por calor ser próximo de zero para o vidro eletrocrômico está relacionado ao fato do vidro barrar a passagem dos raios infravermelhos para o interior do ambiente dificultando o aquecimento. Já os vidros comuns permitem a passagem dos raios infravermelhos, produzindo calor excessivo, pois $50 \%$ da radiação solar está no infravermelho, por este motivo o consumo de energia para refrigeração da edificação é maior com os vidros comuns de $3 \mathrm{~mm}$ e $6 \mathrm{~mm}$ do que com o vidro eletrocrômico. E o inverso acontece com o consumo de energia para aquecimento, onde o vidro eletrocrômico apresenta maior desconforto por frio gerando maior consumo de energia para o aquecimento (Figura 3). 


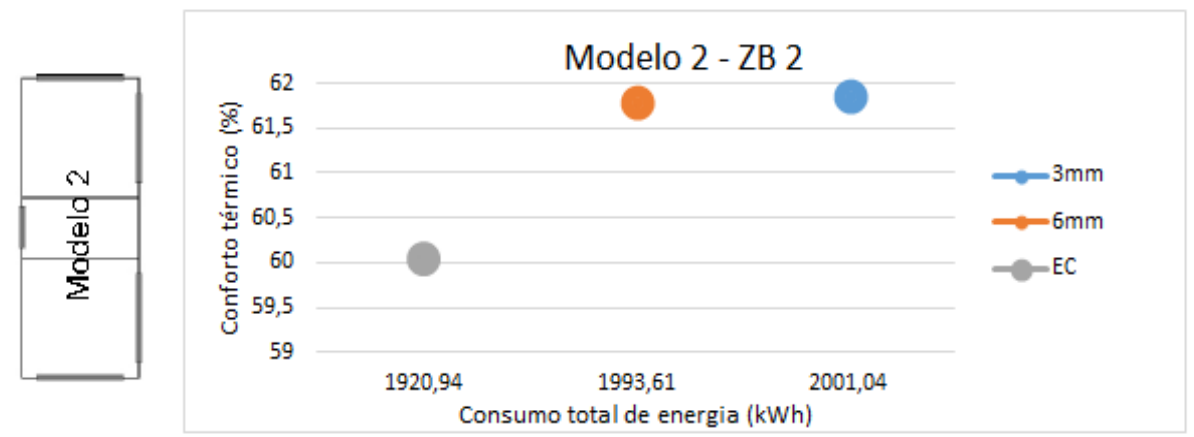

Figura 4: Consumo de energia e conforto térmico do Modelo 2 na ZB2.

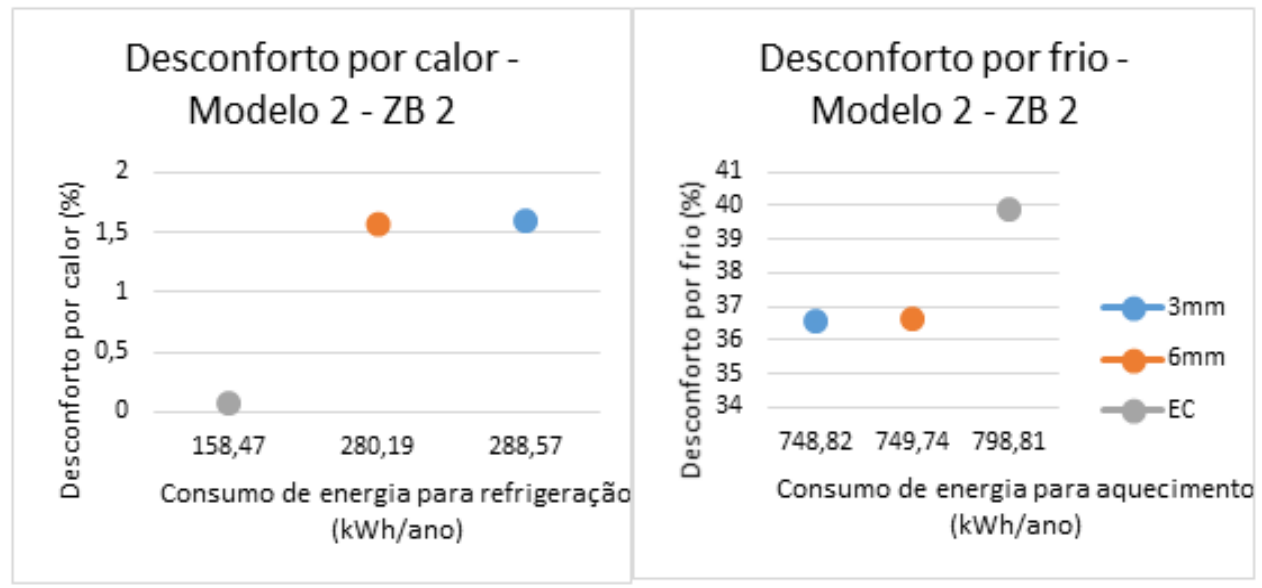

Figura 5: Consumo de energia para aquecimento e refrigeração versus desconforto por calor e frio do Modelo 2 na ZB2.

Para o Modelo 2 o melhor caso simulado é o vidro eletrocrômico e a pior opção de vidro é o comum de $3 \mathrm{~mm}$ (figuras 4 e 5). O Modelo 2 apresenta as janelas da sala 1 voltadas para sul e oeste e as janelas da sala 2 voltadas para sul e leste. Os ganhos solares são menores na fachada sul, ocasionando perdas significativas de calor no inverno, devido à resistência térmica da janela, por isso que neste modelo todos os vidros simulados obtiveram mais horas ocupadas em desconforto por frio e menos horas em conforto térmico, mostrando que as duas janelas voltadas para o sul, não são benéficas para o conforto térmico dos usuários.

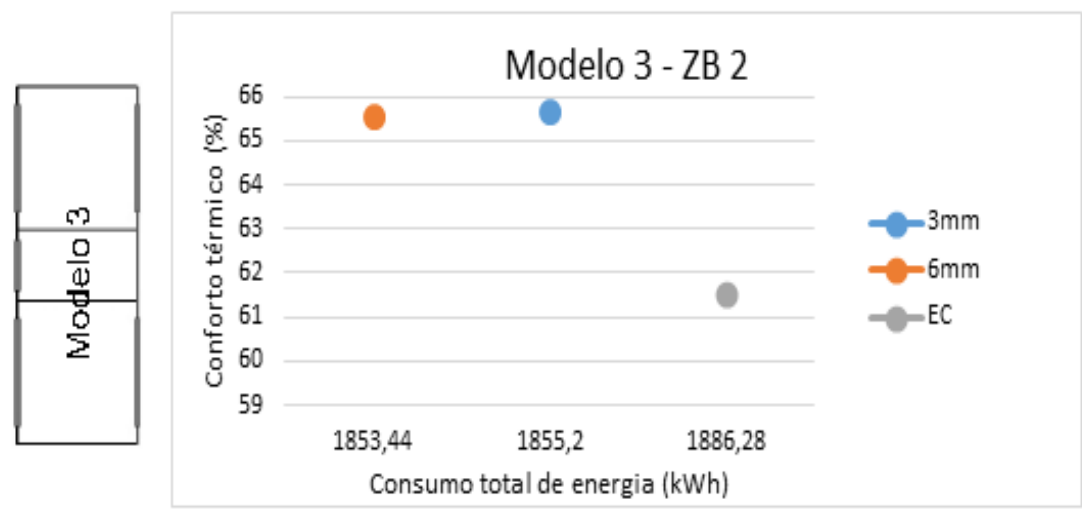

Figura 6: Consumo de energia e conforto térmico do Modelo 3 na ZB2. 


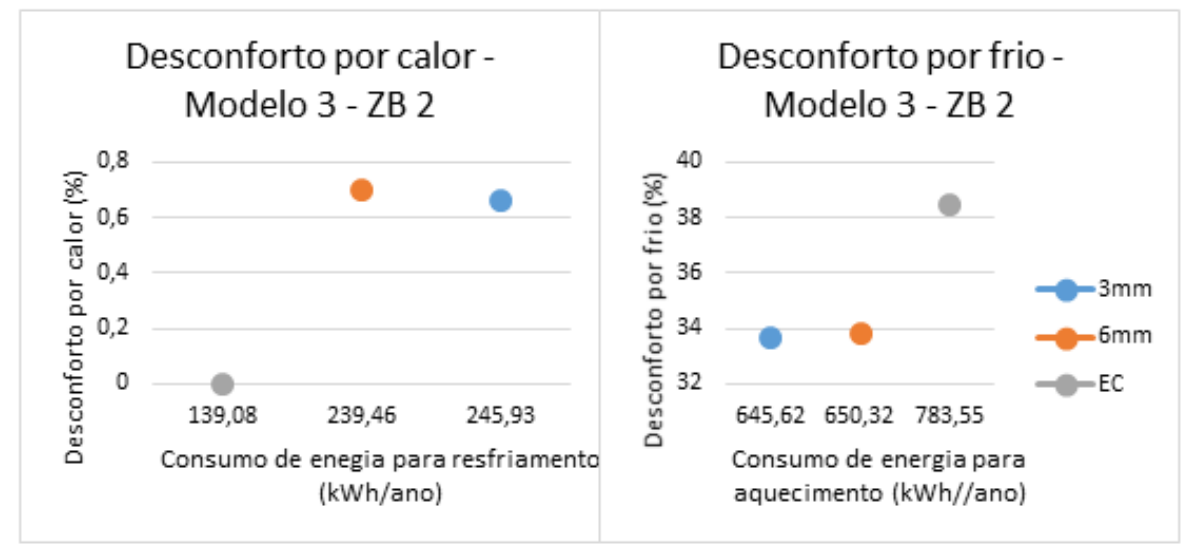

Figura 7: Consumo de energia para aquecimento e refrigeração versus desconforto por calor e frio do Modelo 3 na ZB2.

A edificação do Modelo 3, têm as janelas das duas salas com o mesmo posicionamento solar, uma voltada para norte e outra para o sul. Este modelo foi a que apresentou mais horas ocupadas em conforto térmico com os três tipos de vidros, como mostra a figura 6. Também é possível observar que o vidro eletrocrômico não obteve percentual de horas em desconforto por calor na edificação do Modelo 3. Assim, podemos concluir que a orientação das janelas nas fachadas norte e sul foi uma boa escolha.

Destaca-se que a edificação do Modelo 3, obteve o menor consumo total de energia e o menor consumo para resfriamento, este fato ocorreu devido ao posicionamento das janelas (norte e sul) na edificação.

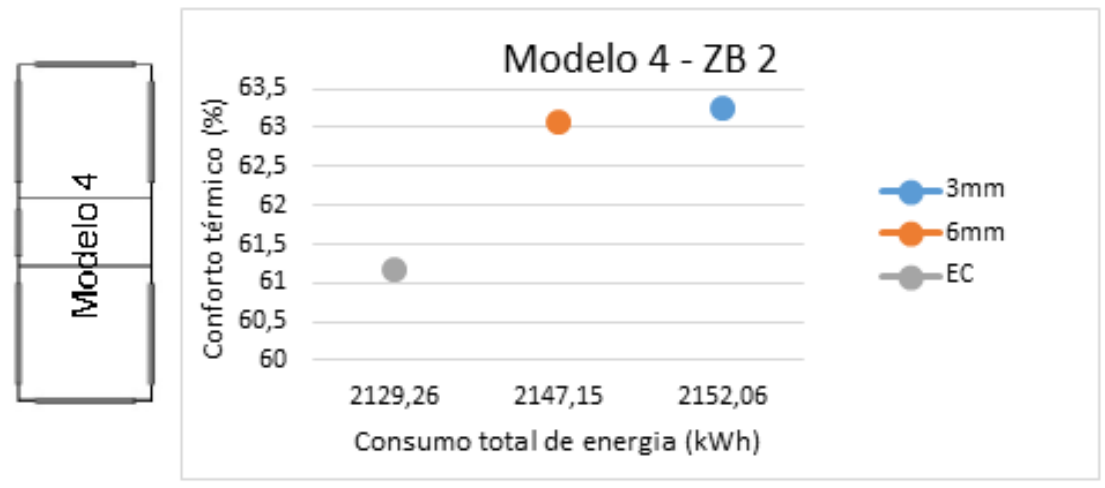

Figura 8: Consumo de energia e conforto térmico do Modelo 4 na ZB2.

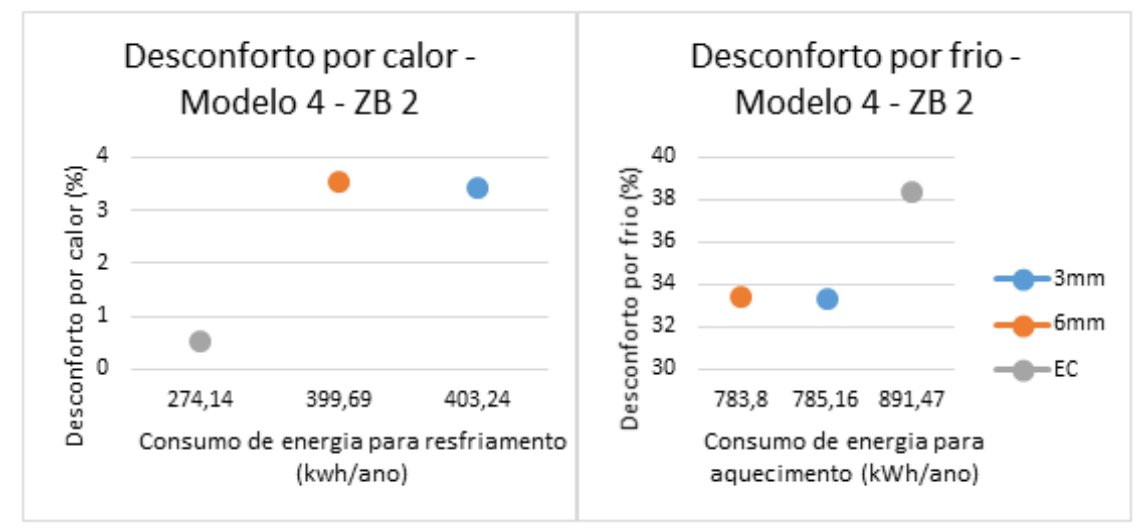

Figura 9: Consumo de energia para aquecimento e refrigeração versus desconforto por calor e frio do Modelo 3 na ZB2. 
Na edificação do Modelo 4, as janelas da sala 1 estão voltadas para o norte, sul e oeste e as janelas da sala 2 estão voltadas para norte, sul e leste. A edificação do Modelo 4 foi a que apresentou mais horas em desconforto por calor, tal desconforto foi ocasionado pela quantidade de janelas existentes nessa edificação, todos os outros modelos tinham duas janelas em cada sala e este modelo possui três janelas. Assim, podemos afirmar que as condições adequadas de orientação e uma grande área de janelas, contribuem de forma expressiva para as condições de conforto térmico dos usuários.

Neste caso, o vidro eletrocrômico obteve melhor desempenho tanto no consumo total como para o consumo de energia gasto para resfriar os ambientes (figuras 8 e 9). Em todos os casos simulados o vidro eletrocrômico apresentou maior desconforto por frio, este comportamento é devido ao fato que o vidro eletrocrômico bloqueia a radiação solar impedindo que os raios infravermelhos entrem na edificação evitando o aquecimento da mesma.

É possível observar que no Modelo 3, o qual é considerado o melhor em relação a orientação solar das janelas (fachadas norte e sul), o vidro eletrocrômico não obteve o melhor desempenho, e que nos demais modelos simulados na ZB 2 o vidro eletrocrômico é melhor pois, há indícios que sua mudança de coloração (descolorido/colorido) minimiza as questões relativas a orientação solar. Na orientação norte no verão temos a maior altura na trajetória aparente do sol, este é um dos indícios do menor consumo de energia para resfriamento com o vidro eletrocrômico. No inverno, a altura na trajetória aparente solar é menor ocasionando maior consumo de energia para aquecimento.

Pode-se observar também que em todos os casos simulados com vidro eletrocrômico, o consumo para resfriamento diminui gradativamente conforme aumenta a coloração do vidro e para o aquecimento o consumo de energia aumenta conforme o vidro torna-se mais escuro.

\subsubsection{Conforto térmico e consumo de energia para ZB 8}

As simulações do consumo de energia para a ZB8, tiveram as mesmas configurações que as simulações realizadas para a ZB2, com alteração no arquivo climático e na temperatura de setpoints.

Diferente dos resultados encontrados nas simulações de conforto térmico na ZB 2, o vidro eletrocrômico obteve excelentes resultados alcançando melhor desempenho que os outros vidros analisados, para as simulações na ZB 8 por ser uma zona bioclimática com temperaturas elevadas, mostrando assim, que o vidro eletrocrômico é uma ótima opção quando comparado aos outros vidros (figura 10).

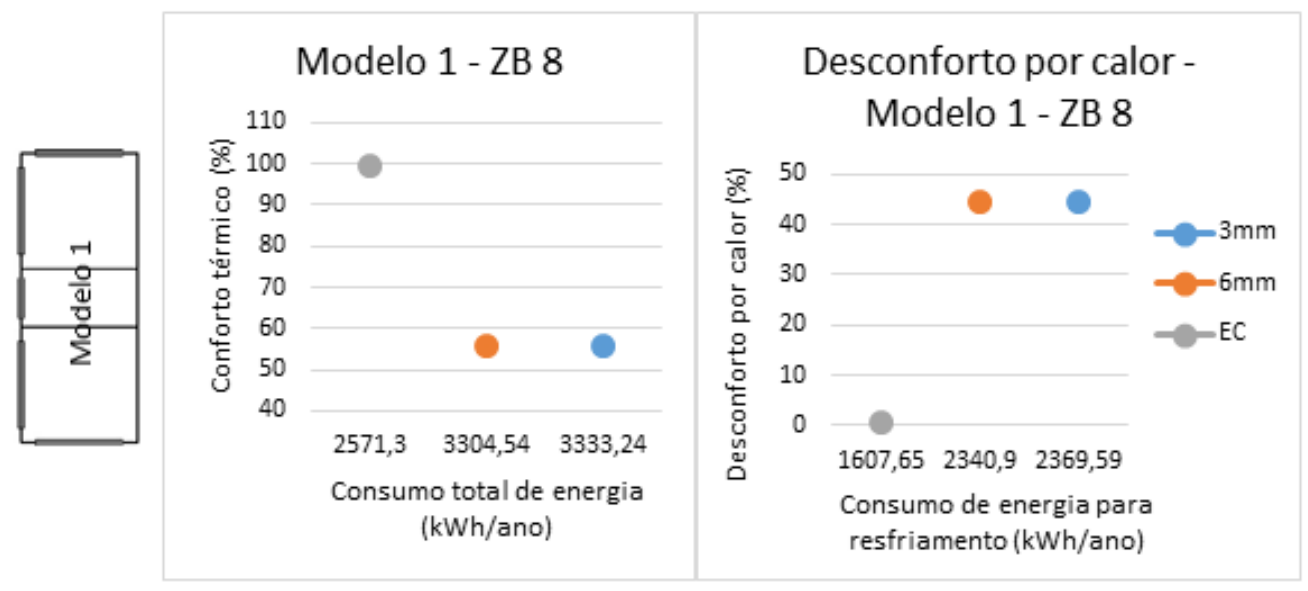

Figura 10: Consumo de energia e conforto térmico do Modelo 1 na ZB 8.

Os vidros eletrocrômicos têm uma importante função na melhoria do conforto térmico das edificações, pois bloqueia os raios infravermelhos diminuindo a temperatura no interior da edificação, o que é importantíssimo para uma região onde os climas quentes são intensos.

Apesar da edificação do Modelo 1 ter duas janelas voltadas para o norte, a edificação teve maior consumo de energia total e para resfriamento, tendo relação direta com o posicionamento das janelas para o oeste e leste, portanto, o posicionamento das janelas na edificação tem influência direta no conforto térmico, por se tratar de um clima quente, é imprescindível que o controle da radiação solar seja feito de maneira adequada. 


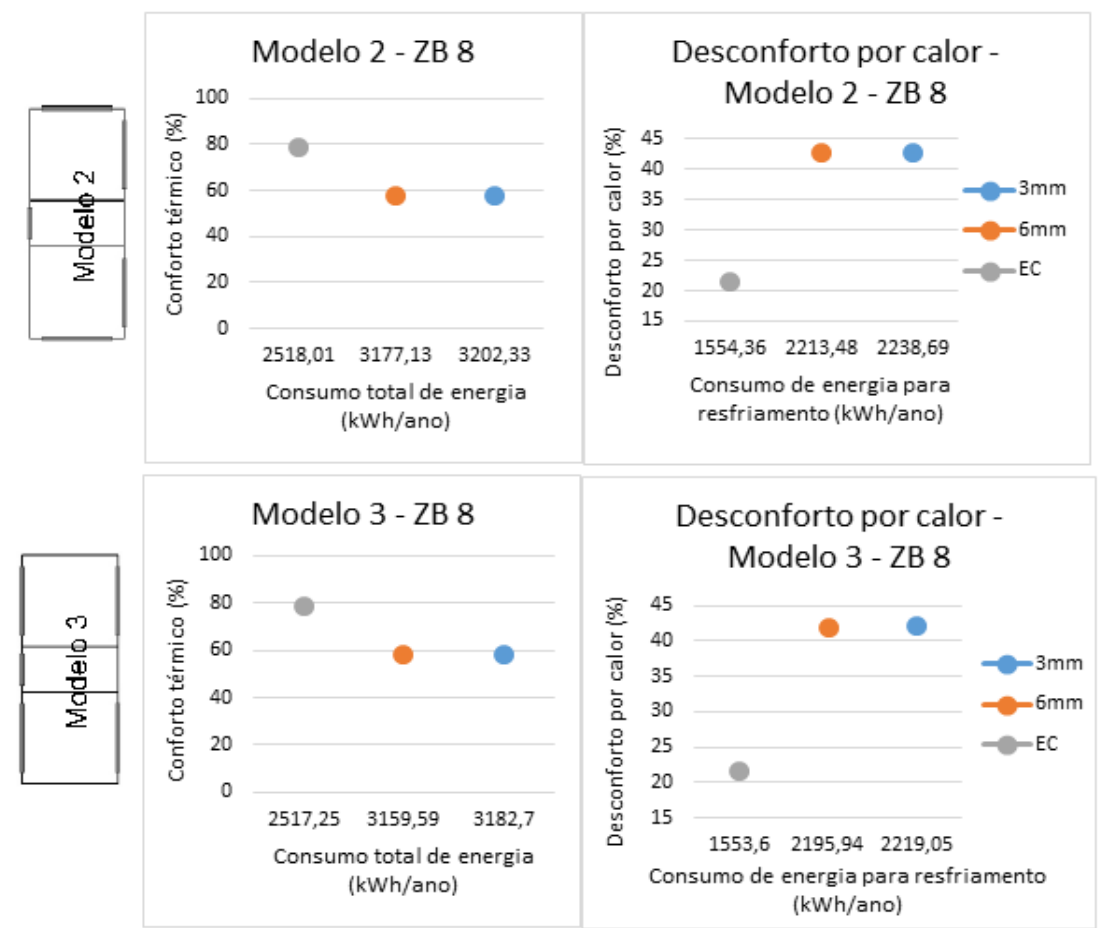

Figura 11: Consumo de energia e desconforto térmico dos Modelo 2 e 3 na ZB 8.

Os resultados encontrados com as simulações das edificações dos Modelos 2 e 3 foram bem semelhantes, como pode ser observado na figura 11. A edificação do Modelo 3 foi a edificação que consumiu menos energia para o resfriamento e para o consumo total nos três tipos de vidros analisados, tal fato está relacionado ao posicionamento das janelas pois, as mesmas estão orientadas para o norte e sul.

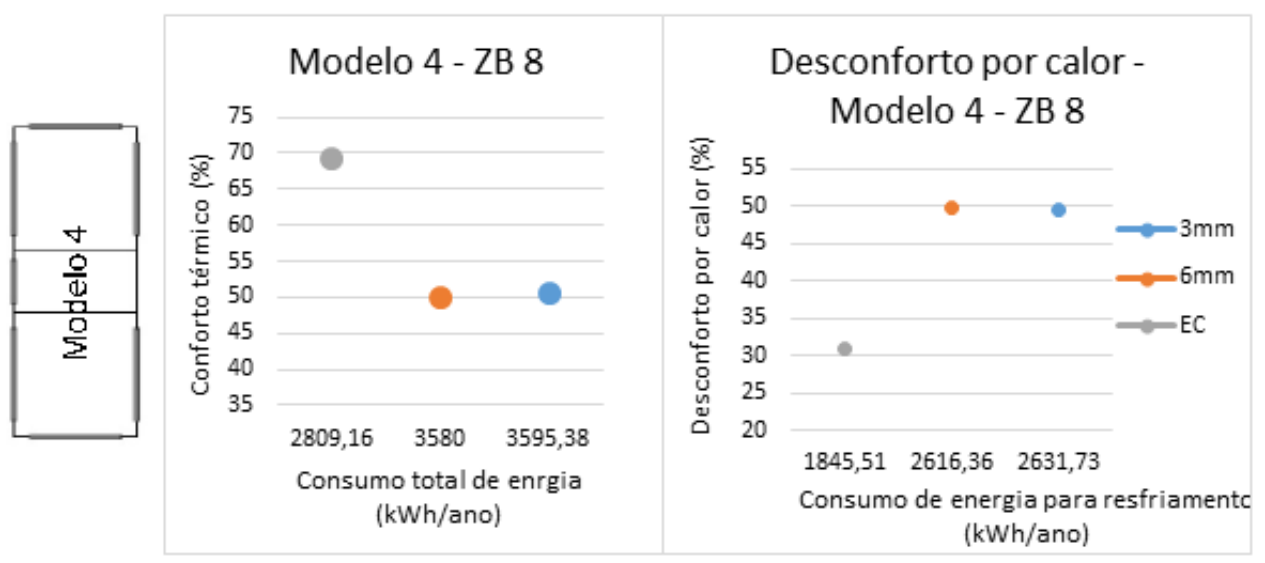

Figura 12: Consumo de energia e desconforto térmico dos Modelo 2 e 3 na ZB 8.

A edificação do Modelo 4 foi a mais dispendiosa com todos os tipos de vidros, o que está relacionado ao número maior de aberturas nas salas 1 e 2, como já mencionado nas análises para ZB 2 (figura 12).

Nota-se que para as duas zonas bioclimáticas analisadas, as edificações que possuem janelas nas fachadas leste e oeste são as que mais consumiram energia, portanto, a orientação das aberturas é fundamental além da escolha adequada do tipo de vidro.

Através das simulações observou-se que o vidro eletrocrômico consumiu menos energia total e menos energia para o resfriamento em todos os casos, e que os vidros Comum de $3 \mathrm{~mm}$ foi o que mais consumiu energia total e energia para resfriamento (figuras 10, 11 e 12). Por ser uma região de clima quente, o controle da radiação solar é fundamental tendo um impacto maior no desempenho do edifício. 


\subsection{Iluminação}

Com as análises de iluminação foi observado que os vidros eletrocrômicos não apresentaram um bom desempenho em relação aos vidros comuns quando se utiliza o método de autonomia de luz natural (DA) para a análise da iluminação. Já quando é utilizado o método da iluminância natural útil (UDI), os vidros eletrocrômicos apresentaram um desempenho superior em relação aos vidros comuns. Todos os resultados podem ser observados nas figuras 13 e 14 .

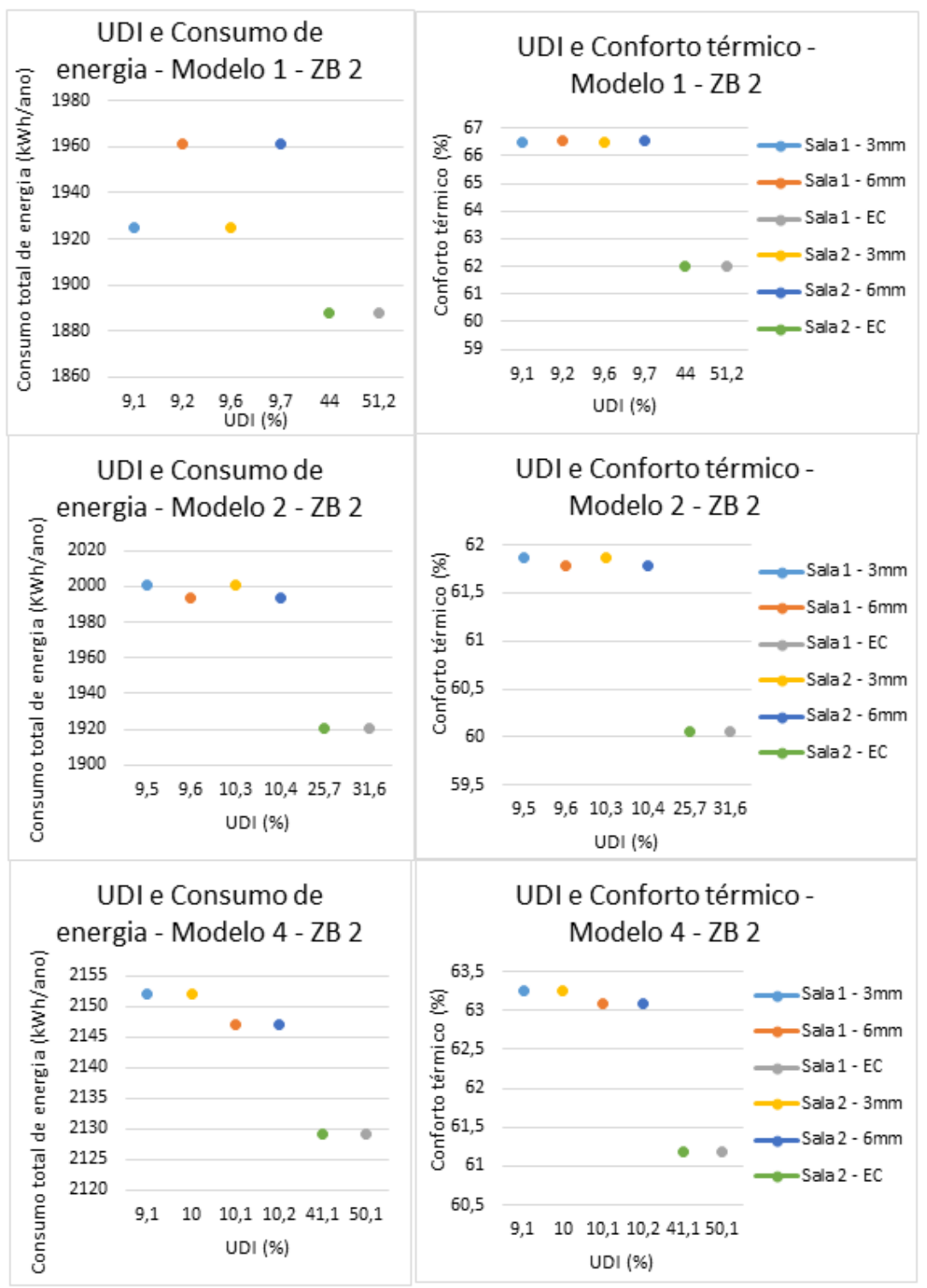

Figura 13: Avaliação da iluminação natural dos ambientes nos Modelos 1, 2 e 4.

É possível observar que os vidro eletrocrômico consumiu menos energia e que teve maior índice de iluminância nos Modelos 1, 2 e 4 e, que nestes modelos o vidro obteve menos horas em conforto térmico. Já o Modelo 3, foi o modelo em que o vidro eletrocrômico consumiu mais energia (figuras 13 e 14). Observando as figuras 13 e 14 nota-se que não são encontradas diferenças significativas entre os Modelos (variações de orientação solar) e entre as diferentes zonas bioclimáticas, a única diferença mais significativa foi observada com a utilização dos vidros eletrocrômicos no Modelo 2 com zona bioclimática 2, esse modelo apresentou apenas $31,6 \%$ e $25,7 \%$ de horas com iluminância entre 100 lux e 2000 lux. O que pode ser explicado facilmente, já que a cidade utilizada para representar a zona bioclimática 2 possui uma latitude sul, logo a orientação solar sul não recebe muita incidência solar ao longo do ano. 


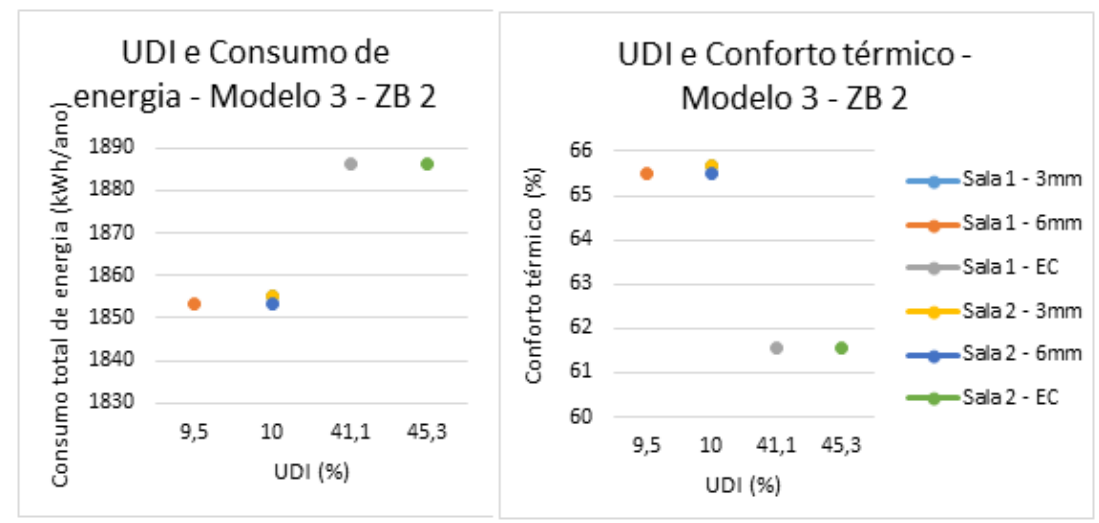

Figura 14: Avaliação da iluminação natural dos ambientes.

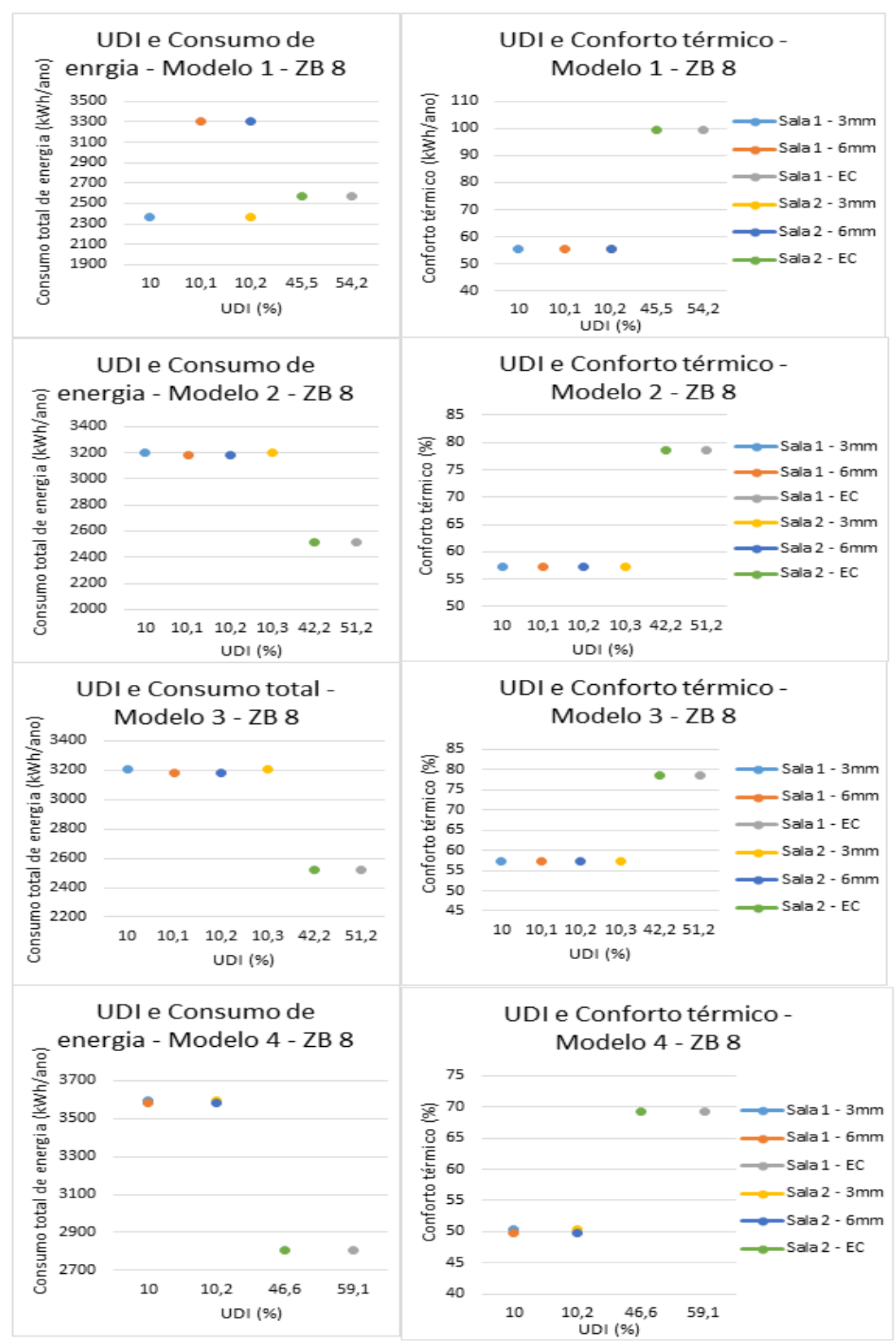

Figura 15: Avaliação da iluminação natural dos ambientes. 
Para a ZB 8 o vidro eletrocrômico, além de ter apresentado menor consumo e mais horas em conforto térmico, foi o que obteve maiores índices de iluminância (figura 15).

Nota-se também que com a utilização dos vidros eletrocrômicos, em nenhum momento do ano, em nenhuma orientação solar e zona bioclimática, a iluminância atinge 500lux. Acredita-se que esse fator possa estar envolvido com a configuração dos vidros na simulação, com outras configurações talvez o vidro tivesse um desempenho melhor. Os vidros comuns apresentam melhor desempenho no método DA, mas deve ser levado em consideração que nesse método pode ter horas com iluminação em excesso, já que este método não coloca limite máximo.

Os resultados apontam que em todos os casos simulados para a ZB 2 o vidro eletrocrômico apresenta melhor desempenho, pois ele apresentou menor número de horas com iluminância acima de 2000 lux em comparação aos vidros de $3 \mathrm{~mm}$ e $6 \mathrm{~mm}$, esse é um dos motivos pelo qual ele apresenta mais horas em conforto térmico que os demais.

\section{CONCLUSÕES}

Devido ao fato do dispositivo eletrocrômico bloquear a radiação solar o que impedi a entrada dos raios infravermelhos na edificação, ele apresentou maior desconforto por frio evitando o aquecimento da edificação, nos casos analisados, na ZB 2. Isso quer dizer neste caso estes dispositivos são melhores aproveitados em climas com altas temperaturas, predominantemente região norte do Brasil. Das simulações realizadas que o vidro eletrocrômico obteve melhor desempenho quando comparado com os outros vidros na zona bioclimática 8, por se tratar de uma região muito quente, onde o controle de radiação solar é fundamental, sendo assim uma ótima opção de vidro.

O posicionamento das janelas na edificação relaciona-se diretamente com o conforto térmico do usuário, sendo inevitável que o controle da radiação solar seja feito adequadamente, assim como observou-se que em todos os casos simulados com vidro eletrocrômico, o consumo para resfriamento diminui gradativamente conforme aumenta a coloração do vidro e para o aquecimento o consumo de energia aumenta conforme o vidro torna-se mais escuro.

Para o caso do ZB 2 existe um balanço entre os resultados gerados nas simulações realizadas salas com o vidro eletrocrômico em relação aos outros vidros, ou seja, o vidro eletrocrômico de um modo geral consome menos energia total na edificação, porque ele consome mais energia para aquecimento e menos energia para o resfriamento. Para a ZB 8 este balanço não existe, porque a energia gasta com aparelhos de ar condicionado é somente para resfriamento.

Para a iluminância os vidros de $3 \mathrm{~mm}$ e $6 \mathrm{~mm}$ são melhores, por serem vidros que estão sempre transparentes, apresentam melhores resultados.

\section{BIBLIOGRÁFICAS}

[1] SARDEIRO, P. S., Parâmetros para a escolha de superfícies translúcidas visando o conforto térmico e visual na edificação. Tese de doutorado, Faculdade de Engenharia Civil, Arquitetura e Urbanismo. Universidade Estadual de Campinas, Campinas- SP, 2007, 221p.

[2] DEFOREST et al., "A comparative energy analysis of three electrochromic glazing technologies in commercial and residential buildings", Applied Energy, v.192, pp. 95 - 109, 2017.

[3] TAVARES P., et al., "Control criteria of electrochromic glasses for energy savings in mediterranean buildings refurbishment”. Sol Energy, v.50, pp.134:236, 2016.

[4] PICCOLO A, SIMONE F. "Performance requirements for electrochromic smart window". Journal of Building Engineering, v.3, pp. 94-103, 2015.

[5] MARDALJEVIC, J., et al., "Neutral daylight illumination with variable transmission glass: theory and validation". Lighting Research and Technology, 48(3), pp.267-285, 2016.

[6] MONK, P.M.S.; MORTIMER, R.J.; ROSSEINSKY, D.R. Electrochromism Fundamentals and Applications, VCH, Weinheim, 1995.

[7] HEUSING, S.; AEGETER, M.A., "Sol-gel coatings for eletrochromic devices". S. Sakka (Ed.), Applications of Sol-Gel Technology, Boston, v.,n.,p.719-740, 2005.

[8] ENGFELDT, J.D. et al., "Methodology for measuring current distribution effects in electrochromic smart Windows". Applied Optics, v. 50, n.29, p.5639-5646, 2011.

[9] DE MELLO, et al., "Solid eletrolytes for electrochromic devices based on reversible metal electrodeposition". Solar Energy Materials and Solar Cells, v. 103, n., p.17-24, 2012. 
[10] SBAR N. L. et al., "Electrochromic dynamic windows for office buildings". International Journal of Sustainable Built Environment, v.1, p.125-139, 2012.

[11] ENERGYPLUS. EnergyPlus Input and Output Reference, EnergyPlus Version 8.4., The Board of Trustees of the University of Illinois and the Regent of the University of California through the Ernest Orlando Lawrence Berkeley National Laboratory, Berkeley, USA, 2016.

[12] FREITAS, J.R.; LEITZKE, R. K.; CLEFF, V.; et al. Análise das Condições de Contorno Para Simulação e Configuração de Ventilação Natural em Prédio Escolar. In: ENTAC 2018- XVII Encontro nacional de tecnologia do ambiente construído, 2018, Foz do Iguaçu. Desafios da Inovação no Ambiente Construído, 2018. v. 17. p. 377-387.

[13] ASSOCIAÇÃO BRASILEIRA DE NORMAS TÉCNICAS. ABNT NBR 16401-1: Instalações de ar-condicionadoSistemas centrais e unitários. Parte 1: Projetos das instalações Rio de Janeiro, 2008.

[14] DE DEAR, R.; BRAGER, G. Developing an adaptive model of thermal comfort and preference. ASHRAE Transactions, 104 (1): 145-167, 1998.

[15] ASHRAE STANDARD 55. Thermal Environmental Conditions for Human Occupancy. American Society of Heating, Refrigerating and Air-Conditioning Engineers, Inc. Atlanta, GA, 2010.

\section{ORCID}

Joseane da Silva Porto Julye Moura de Freitas Raphael D. Caldeira Balboni Suzana Zehetmeyer Treichel Eduardo Grala da Cunha Renie Santos de Mattos Rodrigo Karini Leitzke Camila Monteiro Cholant César Avellaneda https://orcid.org/0000-0002-1717-8572

https://orcid.org/0000-0003-2477-2307

https://orcid.org/0000-0003-2715-6569

https://orcid.org/0000-0002-5237-574X

https://orcid.org/0000-0002-6112-7561

https://orcid.org/0000-0003-1424-7664

https://orcid.org/0000-0002-6752-1025

https://orcid.org/0000-0003-2848-1443

https://orcid.org/0000-0002-8527-8030 